\title{
Cobicistat-boosted darunavir in HIV-1-infected adults: week 48 results of a Phase IIlb, open-label single-arm trial
}

Karen Tashima ${ }^{1 *}$, Gordon Crofoot ${ }^{2}$, Frank L Tomaka ${ }^{3}$, Thomas N Kakuda ${ }^{3}$, Anne Brochot ${ }^{4}$, Tom Van de Casteele ${ }^{5}$, Magda Opsomer ${ }^{5}$, William Garner ${ }^{6}$, Nicolas Margot ${ }^{6}$, Joseph M Custodio ${ }^{6}$, Marshall W Fordyce ${ }^{6}$ and Javier Szwarcberg ${ }^{6}$

\begin{abstract}
Background: Cobicistat is an alternative pharmacoenhancer to ritonavir. In healthy volunteers, darunavir exposure was comparable when darunavir $800 \mathrm{mg}$ once daily was co-administered with cobicistat $150 \mathrm{mg}$ once daily (as single agents or a fixed-dose combination) vs. with ritonavir $100 \mathrm{mg}$ once daily.

Methods: This 48-week, Phase IIIb, single-arm, US multicenter study (NCT01440569) evaluated safety, efficacy and pharmacokinetics of darunavir/cobicistat 800/150 mg once daily (as single agents) plus two investigator-selected nucleoside/tide reverse transcriptase inhibitors (N[t]RTIs) in HIV-1-infected adults. Patients had no darunavir resistance-associated mutations (RAMs), plasma viral load (VL) $\geq 1000$ HIV-1 RNA copies/ml, eGFR $\geq 80 \mathrm{ml} / \mathrm{min}$ and genotypic sensitivity to the two N[t]RTIs. The primary endpoint was any treatment-emergent grade 3 or 4 adverse events (AEs) through Week 24.

Results: The majority of the 313 intent-to-treat patients were treatment-naïve (295/313; 94\%), male (89\%), White $(60 \%)$ and received a tenofovir-based regimen (99\%). Median baseline $\mathrm{VL}$ and $\mathrm{CD} 4^{+}$count overall were $4.8 \log _{10}$ HIV-1 RNA copies/ml and 361 cells $/ \mathrm{mm}^{3}$, respectively. Overall, 86\% of patients (268/313) completed the study. The majority of discontinuations were for AEs (15/313; 5\%). The incidence of treatment-emergent grade 3 or 4 AEs regardless of causality was $6 \%$ through Week 24 and $8 \%$ through Week 48 . Most common AEs through Week 48 were diarrhea (27\%) and nausea (23\%), which were grade 1 or 2 in severity. Week 48 virologic response rates (\% with VL <50 HIV-1 RNA copies/ml; Snapshot analysis) were $81 \%$ overall and 83\% in treatment-naïve patients; median increases in $\mathrm{CD4}^{+}$count at 48 weeks were 167 and 169 cells $/ \mathrm{mm}^{3}$, respectively. Of 15/313 patients who met the criteria for resistance analysis, one developed a darunavir RAM as a mixture with wild-type $(|84| \mathrm{N})$, without phenotypic resistance to darunavir. The mean population pharmacokinetic-derived darunavir areas under the plasma concentration-time curve were 102,000 overall and 100,620 ng $\cdot \mathrm{h} / \mathrm{ml}$ in treatment-naïve patients. No clinically relevant relationships were seen between darunavir exposure and virologic response, AEs or laboratory parameters.
\end{abstract}

Conclusion: Darunavir/cobicistat 800/150 mg once daily was generally well tolerated through Week 48, with no new safety concerns. Pharmacokinetics, virologic and immunologic responses for darunavir/cobicistat were similar to previous data for darunavir/ritonavir 800/100 mg once daily.

Keywords: Cobicistat, Darunavir, Safety, Efficacy, Virology, Pharmacokinetics

\footnotetext{
* Correspondence: ktashima@lifespan.org

${ }^{1}$ Alpert Medical School of Brown University, The Miriam Hospital, 164 Summit

Avenue, Providence, RI 02906, USA

Full list of author information is available at the end of the article
} 


\section{Introduction}

Treatment guidelines for HIV-1 infection [1-4] include the recommendation of a ritonavir-boosted protease inhibitor (PI), such as darunavir/ritonavir, in combination with other antiretrovirals. In two randomized, controlled Phase III trials, darunavir/ritonavir $800 / 100 \mathrm{mg}$ once daily demonstrated antiviral efficacy with long-term tolerability in treatment-naïve (ARTEMIS; TMC114-C211) [5-7] and treatment-experienced patients with no darunavir resistance-associated mutations (RAMs) (ODIN; TMC114-C229) [8].

Low-dose ritonavir (100 mg once daily or twice daily) is used as a pharmacokinetic enhancer [9]. Ritonavir is a potent inhibitor of cytochrome P450 (CYP) 3A, and thereby increases the oral bioavailability of most HIV-1 PIs, including darunavir $[9,10]$. Low-dose ritonavir is associated with gastrointestinal disorders, such as diarrhea and nausea [9], hyperlipidaemia [11], and also clinically significant drug-drug interactions [12].

Cobicistat (GS-9350) is also a potent inhibitor of CYP3A and a pharmacoenhancer [13-16]. Cobicistat has no antiviral activity, does not induce CYP isozymes, and is more selective than ritonavir in terms of CYP3A inhibition $[13,14]$. Cobicistat can be coformulated into fixeddose combinations [17], thereby reducing pill burden and medication errors [18-22]. Cobicistat has been evaluated as part of a single-tablet regimen with elvitegravir, emtricitabine and tenofovir in clinical studies of HIV-1-infected, antiretroviral treatment-naïve adults [15,16,23-28]. Cobicistat $150 \mathrm{mg}$ once daily for 144 weeks was generally well tolerated. Small decreases in estimated glomerular filtration rate calculated using the Cockcroft-Gault method (eGFR $\mathrm{CG}_{\text {G }}$ ) were observed with cobicistat in these studies, which are attributable to inhibition of the tubular secretion of creatinine leading to creatinine increases as early as Week 2 and stabilizing by Week 24 through Week 144, without affecting renal function (actual GFR, aGFR) as measured by iohexol renal clearance [29].

A fixed-dose formulation of darunavir/cobicistat has been developed. A Phase I study demonstrated comparable darunavir pharmacokinetic parameters following darunavir $800 \mathrm{mg}$ once daily co-administered with cobicistat $150 \mathrm{mg}$ once daily, either as single agents [30] or as two candidate fixed-dose combination formulations [31] to those of darunavir/ritonavir 800/100 mg once daily. Bioequivalence of darunavir administered as a fixed-dose combination with cobicistat vs. single agents, was established under fasted or fed conditions [32].

The aim of this Phase IIIb study was to evaluate the safety, tolerability, efficacy and pharmacokinetics of darunavir in combination with cobicistat (as single agents) with a background regimen of two, fully active, investigatorselected nucleoside/tide reverse transcriptase inhibitors
(N[t]RTIs) in HIV-infected treatment-naïve and -experienced adults with no darunavir RAMs.

\section{Results}

\section{Patient disposition and baseline characteristics}

The first patient in the study began treatment on October 24 2011, and the last patient in the study had their Week 48 visit on January 312013.

Of the 397 patients screened, 313 were enrolled and included in the intent-to-treat (ITT) population (Figure 1). One patient was not treated. Most of the 83 screening failures were due to screening eGFR CG $<80 \mathrm{ml} / \mathrm{min}$ or screening viral load (VL) $<1000$ HIV-1 RNA copies/ml. Of the 313 ITT patients, 295 were treatment-naïve and 18 were treatment-experienced with no darunavir RAMs. Overall, $86 \%$ of the ITT patients $(268 / 313)$ completed the study and 14\% (45/313) discontinued, mainly for AEs $(n=15)$ and loss to follow-up $(\mathrm{n}=13)$ (Figure 1).

Overall, most patients were male (89\%) and were White $(60 \%)$ or Black or of African Heritage (35\%). The median age was 35 years (range 18 to 72 years) (Table 1). Median (range) baseline $\mathrm{VL}$ and $\mathrm{CD} 4^{+}$cell count were 4.8 (2.6 to 7.0) $\log _{10}$ HIV-1 RNA copies/ml and 361 (5 to 1473) cells/ $\mathrm{mm}^{3}$, respectively. Overall, $2 \%$ of patients were coinfected with hepatitis $\mathrm{B}$ and $3 \%$ with hepatitis $\mathrm{C}$ virus. Baseline characteristics of the treatment-naïve patient population are shown in Table 1.

At baseline, one or more primary PI RAMs were found in 10 patients (3\%; nine treatment-naïve, and one treatment-experienced), most commonly M46I/L (three treatment-naïve and one treatment-experienced) and Q58E (four treatment-naïve). No patients had darunavir RAMs. Secondary PI RAMs were found in $96 \%$ of patients (300/313; 283 and 17 patients), reflecting the strong polymorphic nature of these mutations. Non-nucleoside reverse transcriptase inhibitor (NNRTI) RAMs were found in $28 \%$ of patients $(87 / 313 ; 74$ and 13 patients), most commonly K103N/S (13\%; 41/313; 33 and eight patients). N[t] RTI RAMs were found in $14 \%$ of patients $(43 / 313 ; 36$ and seven patients), most commonly V118I $(6 \% ; 18 / 313 ; 18$ and zero patients), T69D/N (3\%; 8/313; eight and zero patients) and M184V/I (3\%; 8/313; two and six patients).

\section{Concomitant N[t]RTI use}

The majority of patients (99\%; 311/313 overall and 294/ 295 treatment-naïve patients) received tenofovir-based antiretroviral therapy during the study. The most frequently used N[t]RTI combination was emtricitabine/ tenofovir (Table 1).

\section{Adherence}

During the course of the study, median adherence to darunavir and cobicistat in the overall population through Week 48 as measured by pill count was 100\%, and 299/313 


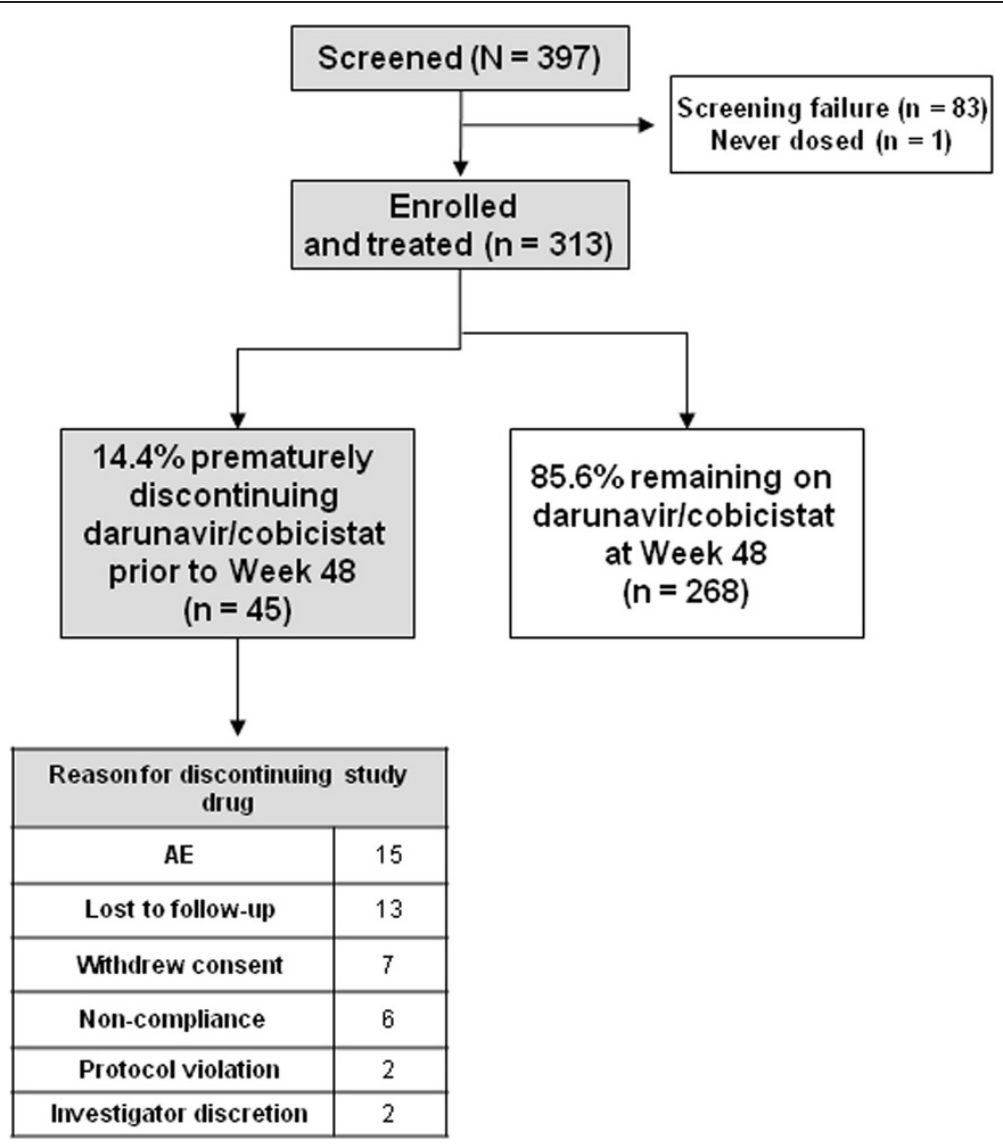

Figure 1 Patient disposition through 48 weeks in the overall population.

patients (96\%) had a $\geq 90 \%$ adherence rate. Median adherence to darunavir and cobicistat in the treatment-naïve population through Week 48 as measured by pill count was also $100 \%$, and $283 / 295$ patients (96\%) had a $\geq 90 \%$ adherence rate.

\section{Safety and tolerability}

The overall median duration of exposure to study drugs was 64.3 weeks (58.3 to 69.3 weeks); 268/313 (86\%) patients received the study drugs for $\geq 48$ weeks.

The most commonly reported treatment-emergent AEs regardless of causality during the study were diarrhea, nausea, upper respiratory tract infection and headache (Table 2). The most common study drug-related AEs through Week 48 were diarrhea (15\%; 47/313 overall and 15\%; 43/295 treatment-naïve patients), nausea (14\%; 45/313 and $15 \% ; 44 / 295$, respectively), headache $(4 \% ; 13 / 313$ and $4 \% ; 12 / 295)$ and flatulence (4\%; $13 / 313$ and 4\%; 13/295).

Most adverse events (AEs) were grade 1 or 2 in severity. The incidence of any grade 3 or 4 treatment-emergent AEs regardless of causality through Week 24 (primary endpoint) was low (Table 2). Overall, 16 patients experienced grade $3(5 \%)$ and two patients experienced grade 4 (0.6\%) AEs. Among the treatment-naïve patients, through
Week 48, the most common grade 3 or 4 AEs regardless of causality (occurring in $\geq 2$ patients) were hypersensitivity (grade 3: two patients; grade 4: one patient), maculo-papular rash (grade 3: two patients) and peripheral neuropathy (grade 3: two patients). Any study drugrelated grade $3 \mathrm{AE}$ occurred in five patients (2\%). These grade 3 AEs were immune reconstitution syndrome (one patient), hypersensitivity (two patients), maculo-papular rash (one patient), and allergic dermatitis, maculo-papular rash and vesicular rash (all occurring in the same patient), and all led to study drug discontinuation. One patient had grade 4 thrombocytopenic purpura, which was considered serious and led to study drug discontinuation, but was not considered related to study drug. Another patient had grade 4 hypersensitivity, which was considered serious and led to study drug interruption, but was not considered related to study drug, but related to concomitant lisinopril.

Three serious AEs, all occurring in treatment-naïve patients, were felt to be related to study drug. One patient each reported immune reconstitution syndrome, rash and maculo-papular rash. There were no deaths. The most commonly reported AEs that led to discontinuation through Week 48 were rash and maculo-papular rash, nausea and hypersensitivity (Table 2). All these AEs were 
Table 1 Patient baseline demographics and disease characteristics and background N[t]RTIs

\begin{tabular}{|c|c|c|}
\hline & All patients $\mathrm{N}=313$ & Treatment-naïve patients $\mathrm{N}=295$ \\
\hline Male $[n(\%)]$ & $279(89)$ & $266(90)$ \\
\hline Age, years [median (range)] & $35(18-72)$ & $34(18-72)$ \\
\hline \multicolumn{3}{|l|}{ Race $[n(\%)]$} \\
\hline White & $187(60)$ & $176(60)$ \\
\hline Black or African Heritage & $108(35)$ & $101(34)$ \\
\hline Asian & $4(1)$ & $4(1)$ \\
\hline Other & $14(4)$ & $14(5)$ \\
\hline $\log _{10}$ VL (HIV-1 RNA copies/ml) [median (range)] & $4.8(2.6-7.0)$ & $4.8(2.6-7.0)$ \\
\hline VL >100,000 HIV-1 RNA copies/ml [n (\%)] & $131(42)$ & $122(41)$ \\
\hline $\mathrm{CD}^{+}$cell count (cells $/ \mathrm{mm}^{3}$ ) [median (range)] & $361(5-1473)$ & $370(6-1473)$ \\
\hline$\leq 200$ cells $/ \mathrm{mm}^{3}[\mathrm{n}(\%)]$ & $59(19)$ & $47(16)$ \\
\hline Asymptomatic HIV infection [n (\%)] & $251(80)$ & $241(82)$ \\
\hline Co-infection with HBV [n (\%)] & $5(2)$ & $5(2)$ \\
\hline Co-infection with HCV [n (\%)] & $8(3)$ & $7(2)$ \\
\hline eGFR ${ }_{C G}, \mathrm{ml} /$ min [median (range)] & $114(67-321)$ & $115(67-321)$ \\
\hline \multicolumn{3}{|l|}{ Background N[t]RTIs [n (\%)] } \\
\hline Emtricitabine/tenofovir & $301(96)$ & $291(99)$ \\
\hline Emtricitabine/tenofovir plus zidovudine & $5(2)$ & 0 \\
\hline Abacavir plus tenofovir & $3(1)$ & $2(0.7)$ \\
\hline Emtricitabine/tenofovir plus abacavir & $2(0.6)$ & $1(0.3)$ \\
\hline Abacavir/lamivudine & $1(0.3)$ & $1(0.3)$ \\
\hline Didanosine plus emtricitabine & $1(0.3)$ & 0 \\
\hline
\end{tabular}

$N$ number of patients; $n$ number of patients with observations; $V L$ viral load; $H B V$ hepatitis B virus; $H C V$ hepatitis $C$ virus; eGFR $R_{C G}$ estimated glomerular filtration rate calculated using the Cockcroft-Gault method; N[t]RTIs nucleoside/tide reverse transcriptase inhibitors.

felt to be study drug-related and resolved upon discontinuation. One treatment-naïve patient discontinued because of renal tubular disorder, which was mild in severity, not serious and resolved following change in therapy to darunavir/ritonavir plus lamivudine and abacavir. Eight bone fractures were reported through Week 48, each with traumatic mechanisms and without features concerning for fragility fracture.

There was an increase in serum creatinine level from baseline occurring as early as Week 2 (median change = $0.10 \mathrm{mg} / \mathrm{dl}$ overall and in treatment-naïve patients), which remained stable throughout the Week 48 treatment period (median change $=0.09 \mathrm{mg} / \mathrm{dl}$ and $0.08 \mathrm{mg} / \mathrm{dl}$, respectively) and is consistent with cobicistat inhibition of creatinine secretion. There were no other clinically relevant changes from baseline in median values for other clinical laboratory parameters.

\section{Virologic response}

Overall, the virologic response rate (Food and Drug Administration [FDA] snapshot analysis) was 82\% (258/313) (95\% confidence interval [CI] 78\%, 87\%) at Week 24 and was sustained and durable through Week 48 (81\%; 95\% CI
76\%, 85\%; Table 3 and Figure 2). Virologic failure occurred in $11 \%$ of patients at Week 48 , and $9 \%$ had no virologic data in the Week 48 window.

In treatment-naïve patients, the Week 48 virologic response rate was $83 \%(244 / 295 ; 95 \%$ CI $78 \%, 87 \%)$. Twenty four treatment-naïve patients $(8 \%)$ were classed as virologic failures, and 27 treatment-naïve patients (9\%) had no virologic data in the Week-48 window.

The Week 48 rates of virologic response were comparable in patients who had a baseline VL $\leq 100,000 \mathrm{HIV}-1$ RNA copies/ml or $>100,000 \mathrm{HIV}-1$ RNA copies/ml, both overall ( $81 \%$ vs. $80 \%$, respectively) (Table 3 ) and in treatment-naïve patients ( $84 \%$ vs. $81 \%$ ).

Sensitivity analyses showed the Week 48 virologic response rate was $81 \%(253 / 313)$ overall and $83 \%$ (245/ $295)$ in treatment-naïve patients using the time-to-loss of virologic response (TLOVR) analysis, and it was $83 \%$ $(260 / 313)$ and $85 \%(250 / 295)$, respectively, using the missing $=$ failure $(\mathrm{M}=\mathrm{F})$ method.

\section{Immunologic response}

There was an increase in $\mathrm{CD}^{+}$cell count from baseline at all timepoints following initiation of study drugs. At 
Table 2 Treatment-emergent AEs and grade 3-4 laboratory abnormalities

\begin{tabular}{|c|c|c|c|}
\hline \multirow{3}{*}{ Incidence, [n (\%)] } & \multicolumn{2}{|c|}{ All patients } & \multirow{3}{*}{$\begin{array}{l}\text { Treatment-naïve patients } \\
\begin{array}{c}\text { Week } 48 \text { analysis } \\
\text { N }=295\end{array}\end{array}$} \\
\hline & Week 24 analysis & Week 48 analysis & \\
\hline & $N=313$ & $N=313$ & \\
\hline Grade 3-4 AEs & $18(6)$ & $24(8)$ & $21(7)$ \\
\hline Any AE & $275(88)$ & $286(91)$ & $270(92)$ \\
\hline Any drug-related $\mathrm{AE}$ & $123(39)$ & $128(41)$ & $122(41)$ \\
\hline Serious AEs & $15(5)$ & $26(8)$ & $21(7)$ \\
\hline Deaths & 0 & 0 & 0 \\
\hline
\end{tabular}

AEs any grade, regardless of relationship to study treatment and occurring in $\geq 10 \%$ of patients

$\begin{array}{llll}\text { Diarrhea } & 78(25) & 86(27) & 80(27) \\ \text { Nausea } & 67(21) & 72(23) & 69(23) \\ \text { Upper respiratory tract infection } & 31(10) & 44(14) & 43(15) \\ \text { Headache } & 29(9) & 38(12) & 35(12) \\ \text { AEs leading to discontinuation* } & & & 16(5) \\ \text { Any, } n & 15(5) & 16(5) & 3(1) \\ \text { Maculo-papular rash } & 3(1) & 3(1) & 3(1) \\ \text { Rash } & 3(1) & 3(1) & 2(0.7) \\ \text { Nausea } & 2(0.6) & 2(0.6) & 2(0.7) \\ \text { Hypersensitivity } & 2(0.6) & 2(0.6) & 1(0.3) \\ \text { Idiopathic thrombocytopenic purpura } & 1(0.3) & 1(0.3) & 1(0.3) \\ \text { Dyspepsia } & 1(0.3) & 1(0.3) & 1(0.3) \\ \text { Vomiting } & 1(0.3) & 1(0.3) & 1(0.3) \\ \text { Mycobacterium avium complex infection } & 1(0.3) & 1(0.3) & 1(0.3) \\ \text { Headache } & 1(0.3) & 1(0.3) & 1(0.3) \\ \text { Dysgeusia } & 1(0.3) & 1(0.3) & 1(0.3) \\ \text { Renal tubular disorder } & - & 1(0.3) & 1(0.3) \\ \text { Allergic dermatitis } & 1(0.3) & 1(0.3) & 1(0.3) \\ \text { Macular rash } & 1(0.3) & 1(0.3) & 1(0.3) \\ \text { Vesicular rash } & 1(0.3) & \end{array}$

Treatment-emergent grade 3-4 laboratory abnormalities occurring in $\geq 2 \%$ patients

$\begin{array}{lccc} & \mathbf{n}=\mathbf{3 1 0} & \mathbf{n}=\mathbf{3 1 0} & \mathbf{n}=\mathbf{2 9 2} \\ \text { Increased creatine kinase } & 18(6) & 22(7) & 22(8) \\ \text { Increased alanine amino transferase } & 7(2) & 9(3) & 9(3) \\ \text { Increased aspartate amino transferase } & 6(2) & 8(3) & 7(2) \\ \text { Increased amylase } & 6(2) & 8(3) & 7(2) \\ \text { Increased lipase } & 5(2) & 7(2) & 7(2)\end{array}$

$N$ number of patients; $n$ number of patients with observations; $A E$ adverse event. Serious AEs included any AE that occurred at any dose that resulted in death, a life-threatening situation, inpatient hospitalization, persistent or significant disability/incapacity, congenital anomaly/birth defect in the offspring of a patient who received investigational medicinal product; *Patients may have discontinued due to more than $1 \mathrm{AE}$.

Weeks 24 and 48 in the overall population, the median (range) increases from baseline in $\mathrm{CD} 4^{+}$cell count (missing = excluded) were 131 ( -471 to 596$)$ cells $/ \mathrm{mm}^{3}$ and 167 (-193 to 1086) cells $/ \mathrm{mm}^{3}$, respectively (Figure 2 ). In treatment-naïve patients, the median (range) $\mathrm{CD}^{+}$cell count increased by 169 (-193 to 1086) cells $/ \mathrm{mm}^{3}$ from baseline to Week 48 .

\section{Development of resistance}

Of the 15 patients with samples eligible for resistance analysis (Table 4), three had suboptimal virologic response, eight had virologic rebound, and four who discontinued with VL $\geq 400 \mathrm{HIV}-1$ RNA copies/ml were analyzed at their last visit. Only one of these 15 patients who was treatment experienced (prior antiretrovirals 
Table 3 Virologic outcome at Week 24 and 48 according to the FDA Snapshot* analysis in the overall population

\begin{tabular}{|c|c|c|c|c|c|c|}
\hline \multirow{4}{*}{ Outcomes, [n (\%)] } & \multicolumn{3}{|c|}{ Week 24} & \multicolumn{3}{|c|}{ Week 48} \\
\hline & \multicolumn{2}{|r|}{$\mathrm{VL} \leq 100 \mathrm{~K} \mathrm{HIV}-1$} & $\mathrm{VL}>100 \mathrm{~K} \mathrm{HIV}-1$ & \multicolumn{2}{|r|}{$\mathrm{VL} \leq 100 \mathrm{~K} \mathrm{HIV}-1$} & VL $>100 \mathrm{~K} \mathrm{HIV}-1$ \\
\hline & Total & RNA copies/ml & RNA copies/ml & Total & RNA copies/ml & RNA copies/ml \\
\hline & $n=313$ & $n=182$ & $n=131$ & $n=313$ & $n=182$ & $n=131$ \\
\hline Virologic response & $258(82)$ & $157(86)$ & $101(77)$ & $253(81)$ & $148(81)$ & $105(80)$ \\
\hline Virologic failure & $36(12)$ & $10(5)$ & $26(20)$ & $33(11)$ & $14(8)$ & $19(15)$ \\
\hline VL $\geq 50$ HIV-1 RNA copies/ml & $22(7)$ & $4(2)$ & $18(14)$ & $14(4)$ & $5(3)$ & $9(7)$ \\
\hline Discontinued drug due to lack of efficacy & 0 & 0 & 0 & 0 & 0 & 0 \\
\hline $\begin{array}{l}\text { Discontinued drug due to other reasons and } \\
\text { last available } V L \geq 50 \text { HIV-1 RNA copies/ml }\end{array}$ & $14(4)$ & $6(3)$ & $8(6)$ & $19(6)$ & $9(5)$ & $10(8)$ \\
\hline No virologic data in the analysis window & $19(6)$ & $15(8)$ & $4(3)$ & $27(9)$ & $20(11)$ & $7(5)$ \\
\hline Discontinued drug to $\mathrm{AE}$ & $14(4)$ & $12(7)$ & $2(2)$ & $15(5)$ & $13(7)$ & $2(2)$ \\
\hline $\begin{array}{l}\text { Discontinued drug for other reason and last } \\
\mathrm{VL}<50 \text { HIV-1 RNA copies/ml }\end{array}$ & $3(1)$ & $2(1)$ & $1(1)$ & $10(3)$ & $5(3)$ & $5(4)$ \\
\hline Missing data during window but on drug & $2(1)$ & $1(1)$ & $1(1)$ & $2(1)$ & $2(1)$ & 0 \\
\hline
\end{tabular}

*Proportion of patients with VL $<50$ HIV-1 RNA copies/ml during Week 24 or Week 48 window; $N$ number of patients; $n$ number of patients with observations; $A E$ adverse event, $V L$ viral load.

included efavirenz, emtricitabine, tenofovir disoproxil fumarate, zidovudine, lamivudine, stavudine) developed a resistance mutation to darunavir (at position I84 as a mixture with wild-type, I84I/V) (Table 4); this was not associated with phenotypic resistance to darunavir or other PIs. Two patients (one treatment-experienced and one treatment-naïve) developed the M184V N[t]RTI RAM in reverse transcriptase while receiving emtricitabine (Table 4) that was associated with phenotypic resistance to emtricitabine and lamivudine. One patient (patient 14 in Table 4) showed the transient development of the N[t]RTI RAM L74I/L and the NNRTI RAM $\mathrm{P} 225 \mathrm{H} / \mathrm{P}$ at the Week 16 visit, which were not detected at the subsequent Week 48 visit analysis as shown in Table 4. These mutations were not associated with resistance to the agents in the patient's regimen (emtricitabine/tenofovir/zidovudine), and may reflect previous drug history. New primary RAMs were not detected in the 11 remaining patients.

\section{Pharmacokinetics}

Sixty patients were enrolled in the pharmacokinetic substudy. Pharmacokinetic parameters were comparable to historic data. For darunavir, mean (standard deviation [SD]) maximum plasma concentration $\left(C_{\max }\right)$ was 7663 (1920) $\mathrm{ng} / \mathrm{ml}$, minimum plasma concentration $\left(C_{\min }\right)$ was $1310(969) \mathrm{ng} / \mathrm{ml}$ and area under the concentration-time curve during a 24-hour interval $\left(\mathrm{AUC}_{24 \mathrm{~h}}\right)$ was $81,646(26,322) \mathrm{ng} \cdot \mathrm{h} / \mathrm{ml}$ (Table 5). Pharmacokinetics of cobicistat, tenofovir and emtricitabine are shown in Table 5 .

In the Bayesian feedback analysis for darunavir population pharmacokinetic parameters through Week $48(\mathrm{n}=298)$, the overall mean (SD) population pharmacokinetic- derived darunavir $\mathrm{AUC}_{24 \mathrm{~h}}$ and trough plasma concentration $\left(\mathrm{C}_{0 \mathrm{~h}} ; \mathrm{n}=298\right)$ at Week 48 were 102,000 $(33,100)$ $\mathrm{ng} \cdot \mathrm{h} / \mathrm{ml}$ and 2150 (1320) ng/ml, respectively. Data were available for 281 treatment-naive patients. The mean (SD) darunavir $\mathrm{AUC}_{24 \mathrm{~h}}$ was $100,620(32,366) \mathrm{ng} \cdot \mathrm{h} / \mathrm{ml}$ and $\mathrm{C}_{0 \mathrm{~h}}$ was 2105 (1289) $\mathrm{ng} / \mathrm{ml}$. In 17 treatment-experienced patients, the mean (SD) darunavir $\mathrm{AUC}_{24 \mathrm{~h}}$ was 119,747 $(39,961) \mathrm{ng} \cdot \mathrm{h} / \mathrm{ml}$ and $C_{0 h}$ was 2917 (1658) $\mathrm{ng} / \mathrm{ml}$. These values are comparable to those previously reported for darunavir/ritonavir 800/100 mg once daily (mean [SD] $\mathrm{AUC}_{24 \mathrm{~h}}$ and $\mathrm{C}_{0 \mathrm{~h}}$ were 93,026 [27,050] $\mathrm{ng} \cdot \mathrm{h} / \mathrm{ml}$ and 2282 [1168] $\mathrm{ng} / \mathrm{ml}$, respectively, in antiretroviral-naïve patients [33] and 93,334 [28,626] $\mathrm{ng} \cdot \mathrm{h} / \mathrm{ml}$ and 2160 [1201] $\mathrm{ng} / \mathrm{ml}$, respectively, in treatment-experienced patients with no darunavir RAMs [34]). There were no clinically relevant relationships between darunavir exposure and virologic response, AEs or laboratory parameters.

\section{Discussion}

This Phase IIIb study was conducted to evaluate the safety, efficacy and pharmacokinetics of darunavir/cobicistat 800/ $100 \mathrm{mg}$ once daily in HIV-1-infected adults with no darunavir RAMs who also received two fully active $\mathrm{N}[\mathrm{t}] \mathrm{RTIs}$. We showed that darunavir/cobicistat $800 / 150 \mathrm{mg}$ once daily was well tolerated, and the pharmacokinetics, virologic and immunologic responses were consistent with previously published data for darunavir/ritonavir 800/ $100 \mathrm{mg}$ once daily.

Through Week 24, the onset of any grade 3 or 4 AEs regardless of causality was low (6\% in the overall population). Five out of 313 patients (2\%), all of whom were treatment-naïve, experienced any study drug-related grade 3 AE through Weeks 24 and 48. No patients experienced 


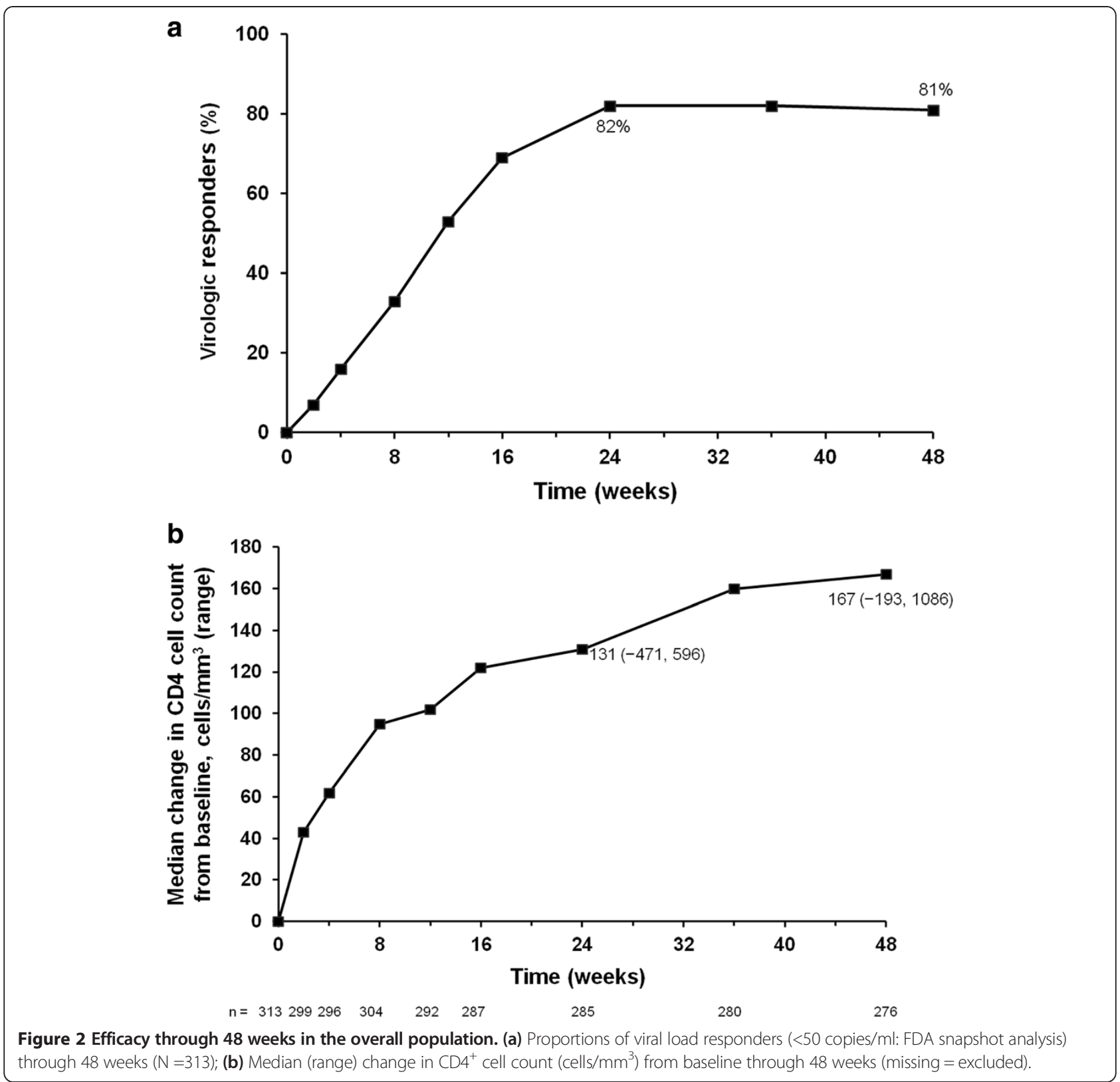

grade 4 drug-related AEs. The most commonly reported AEs of all grades during the study, diarrhea, nausea, upper respiratory tract infection and headache, have all been reported previously for darunavir and cobicistat $[5-8,15,16]$. Renal laboratory assessments showed small changes consistent with the inhibitory effects of cobicistat on renal tubular creatinine secretion rather than a true reduction in GFR [15,16,29].

Darunavir and cobicistat administered once daily with two fully active $\mathrm{N}[\mathrm{t}] \mathrm{RTIs}$, gave a virologic response rate at Week 48 of $81 \%$ overall and $83 \%$ in treatment-naïve patients (FDA Snapshot analysis) and improved CD4 ${ }^{+}$ cell counts over 48 weeks. The Week 48 FDA Snapshot response rate was consistent with responses using secondary analyses, including the TLOVR analysis (81\% response overall and $83 \%$ in treatment-naive patients), and with the Week 48 virologic response rate in treatment-naïve patients in ARTEMIS (84\%; TLOVR, ITT analysis) [5]. As in ARTEMIS, virologic responses were similar irrespective of baseline VL.

In this study, only $15 / 313$ patients met the criteria for resistance analysis. One of these 15 patients who was treatment experienced, developed a darunavir RAM at position I84 as a mixture with wild-type (I84I/V), which was not associated with phenotypic resistance to darunavir or other PIs. Two patients (one treatment experienced and one treatment naïve) developed the M184V RAM while receiving emtricitabine as part of their backbone 
Table 4 Post-baseline genotypic analysis through Week 48 in the 15 patients in the resistance analysis population

\begin{tabular}{|c|c|c|c|c|c|}
\hline \multirow{2}{*}{$\begin{array}{l}\text { Patient } \\
\text { number }\end{array}$} & \multirow[t]{2}{*}{$\mathrm{N}[\mathrm{t}] \mathrm{RTI}$ backbone } & \multirow{2}{*}{$\begin{array}{c}\text { Treatment } \\
\text { cohort }\end{array}$} & \multirow{2}{*}{$\begin{array}{c}\text { Visit } \\
\text { (week) }\end{array}$} & \multicolumn{2}{|r|}{ RAMs emerging* } \\
\hline & & & & Protease & Reverse transcriptase \\
\hline 1 & Abacavir plus tenofovir & Naïve & 24 & None & None \\
\hline 2 & Emtricitabine/tenofovir & Naïve & 12 & None & None \\
\hline 3 & Emtricitabine/tenofovir & Naïve & 48 & |931/L & |142L/P \\
\hline 4 & Emtricitabine/tenofovir & Experienced & 24 & None & $\mathrm{K} 22 \mathrm{~K} / \mathrm{R}$ \\
\hline 5 & Emtricitabine/tenofovir & Naïve & 36 & $\mathrm{R} 57 \mathrm{R} / \mathrm{K}$ & M184V \\
\hline 6 & Emtricitabine/tenofovir & Naïve & 16 & V32V/A, P39P/S & K122K/E, D123D/G/N/S, D177D/G, I178M \\
\hline 7 & Emtricitabine/tenofovir & Naïve & 48 & None & D123D/E \\
\hline 8 & Emtricitabine/tenofovir & Experienced & 48 & None & K122K/E, A272A/P \\
\hline 9 & Emtricitabine/tenofovir & Experienced & 12 & $|84| / V$ & E138T, T165A/E, R211R/K \\
\hline 10 & Emtricitabine/tenofovir & Naïve & 8 & G86G/E & D123N \\
\hline 11 & Emtricitabine/tenofovir plus zidovudine & Experienced & 48 & None & $|195| / L$ \\
\hline 12 & Abacavir plus tenofovir & Experienced & 36 & $\mathrm{R} 41 \mathrm{R} / \mathrm{K}$ & None \\
\hline 13 & Emtricitabine/tenofovir & Naïve & 48 & V77V/I & $\mathrm{E} 6 \mathrm{E} / \mathrm{K}, \mathrm{E} 224 \mathrm{E} / \mathrm{Q}, \mathrm{V} 245 \mathrm{Q}, \mathrm{T} 286 \mathrm{~T} / \mathrm{A}, \mathrm{V} 292 \mathrm{~V} / \mathrm{I}$ \\
\hline 14 & Emtricitabine/tenofovir plus zidovudine & Experienced & 48 & None & $\mathrm{E} 6 \mathrm{E} / \mathrm{D}, \mathrm{V} 60 \mathrm{l}$ \\
\hline 15 & Emtricitabine/tenofovir & Experienced & 36 & None & M184V \\
\hline
\end{tabular}

${ }^{*}$ Compared to screening genotype - emerging primary resistance-associated mutations (RAMs) are shown in bold; N[t]RTI nucleoside/tide reverse transcriptase inhibitor.

$\mathrm{N}[\mathrm{t}] \mathrm{RTI}$ that was associated with phenotypic resistance to both lamivudine and emtricitabine. In the remaining 12 patients who were analyzed for resistance, no new primary RAMs were detected. The low rates of resistance development in this study confirms the high genetic barrier of darunavir whether boosted with cobicistat or ritonavir.

Steady-state darunavir pharmacokinetic parameters in the pharmacokinetic substudy were consistent with those observed in previous Phase I studies in healthy volunteers [30-32]. When data from all evaluable patients were included into a more robust dataset, the population-based darunavir pharmacokinetic parameters were consistent with previous data with darunavir/ritonavir 800/100 mg once daily in HIV-1-infected, treatment-naïve patients in ARTEMIS, and treatment-experienced patients with no darunavir RAMs in ODIN [33,34]. In the population pharmacokinetic model, the mean darunavir $\mathrm{C}_{0 \mathrm{~h}}$ of $2150 \mathrm{ng} / \mathrm{ml}$ was $>37$-fold above the protein-binding adjusted 50\% effective concentration for wild-type virus $(55 \mathrm{ng} / \mathrm{ml})$ [33,35], indicating adequate pharmacokinetic boosting of darunavir by cobicistat.

The mean steady-state cobicistat pharmacokinetic parameters $\left(\mathrm{AUC}_{\text {tau }} 7596 \mathrm{ng} \cdot \mathrm{h} / \mathrm{ml}\right.$ and $\left.\mathrm{C}_{\max } 991 \mathrm{ng} / \mathrm{ml}\right)$ were consistent with levels associated with pharmacokinetic enhancement and in the range of historical data in HIV-1-infected patients $\left(\mathrm{AUC}_{\text {tau }} 8300 \mathrm{ng} \cdot \mathrm{h} / \mathrm{ml}\right.$ and $\mathrm{C}_{\max }$ $1100 \mathrm{ng} / \mathrm{ml}$ ). Steady-state emtricitabine and tenofovir pharmacokinetic parameters were also in the range of historical data [36-38].

No clinically relevant relationship was observed between darunavir $\mathrm{AUC}_{24 \mathrm{~h}}$ or $\mathrm{C}_{0 \mathrm{~h}}$ and virologic response or safety at Week 24 or 48 when given with cobicistat. This is consistent with previous data with darunavir/ritonavir in ARTEMIS [33] and ODIN [34].

The fixed-dose combination of darunavir and cobicistat reduces pill burden compared with separately administered darunavir and ritonavir. Accordingly, the fixed-dose

Table 5 Summary of pharmacokinetic parameters in the substudy

\begin{tabular}{|c|c|c|c|c|}
\hline $\begin{array}{l}\text { Pharmacokinetic parameters } \\
n=60\end{array}$ & Darunavir & Cobicistat & Emtricitabine & Tenofovir \\
\hline$\overline{A \cup C_{\text {tau, }}}$ ng·h/ml [mean (SD)] & $81,646(26,322)^{*}$ & $7596(3657)^{*}$ & $11,793(3490)^{\dagger}$ & $3613(1203)^{\dagger}$ \\
\hline$C_{\max }, \mathrm{ng} / \mathrm{ml}$ [mean (SD)] & $7663(1920)$ & 991 (331) & $1862(491)^{*}$ & $382(118)^{*}$ \\
\hline$C_{\text {tau, }}, \mathrm{ng} / \mathrm{ml}$ [mean (SD)] & $1311(969)^{*}$ & $33(95)^{*}$ & $113(101)^{\dagger}$ & $78(33)^{\dagger}$ \\
\hline $\mathrm{C}_{\mathrm{oh}}, \mathrm{ng} / \mathrm{ml}$ [mean (SD)] & 1560 (1328) & $76(186)$ & $147(171)^{*}$ & $84(45)^{*}$ \\
\hline $\mathrm{T}_{\max }, \mathrm{h}$ [median (Q1, Q3)] & $3.50(2.49,4.29)$ & $3.50(2.01,4.50)$ & $2.02(2.00,3.50)^{*}$ & $2.00(1.00,3.05)^{*}$ \\
\hline $\mathrm{t}_{1 / 2}, \mathrm{~h}$ [median (Q1, Q3)] & $7.24(5.35,11.54)^{\ddagger}$ & $3.25(2.91,3.81)^{*}$ & $7.14(6.44,7.86)^{\S}$ & $13.34(11.68,15.35)^{\S}$ \\
\hline
\end{tabular}

${ }^{*} \mathrm{n}=59 ;{ }^{\dagger} \mathrm{n}=58 ;{ }^{\ddagger} \mathrm{n}=55 ;{ }^{5} \mathrm{n}=56$. 
combination is expected to improve convenience and simplicity, and therefore patient adherence to medication [18-22]. Cobicistat does not induce CYP isozymes and is a more selective inhibitor of CYP3A than ritonavir $[13,14]$, so there is less potential for drug-drug interactions to occur than with ritonavir.

The study was limited in that it was an open-label, single-arm study. As such, it did not directly compare darunavir/cobicistat against darunavir/ritonavir. Nevertheless, previous studies have shown the fixed-dose combination of darunavir/cobicistat $800 / 150 \mathrm{mg}$ once daily has darunavir pharmacokinetic parameters comparable to those of darunavir/ritonavir $800 / 100 \mathrm{mg}$ once daily [30-32]. These comparable pharmacokinetic parameters are expected to translate into similar efficacy, as has been shown in an indirect comparison of darunavir/cobicistat data from the current study and combined darunavir/ritonavir data from ARTEMIS (treatment-naive patients) and ODIN (treatment-experienced patients with no darunavir RAMs) [39].

Secondly, the study included a heterogeneous group of patients with no darunavir RAMs, consistent with the current prescribing information of darunavir $800 \mathrm{mg}$ once daily; however, the majority (94\%) was treatment naive. Separate reporting of the treatment-experienced cohort would not be meaningful given the small number of these patients $(n=18)$.

In conclusion, darunavir and cobicistat was generally well tolerated, and with a safety profile that was consistent with the one of each agent separately. The combination achieved high rates of virologic suppression over 48 weeks, with only one patient developing a darunavir RAM but without phenotypic resistance to darunavir or other PIs. The steady-state pharmacokinetic parameters for darunavir, cobicistat, emtricitabine and tenofovir following administration of darunavir and cobicistat once daily and two fully active $\mathrm{N}[\mathrm{t}] \mathrm{RTI}$ sere consistent with previously published data. These data support the use of darunavir/cobicistat in combination with $\mathrm{N}[\mathrm{t}] \mathrm{RTIs}$ for future treatment of $\mathrm{HIV}$-1-infected patients with no darunavir RAMs.

\section{Methods}

\section{Patients}

Adult HIV-1-infected, treatment-naïve or treatmentexperienced (on a stable antiretroviral regimen for $\geq 12$ weeks prior to screening) patients with no darunavir RAMs were recruited. Patients were required to have plasma VL $\geq 1000$ HIV-1 RNA copies/ml (Amplicor HIV-1 Monitor Test, version 1.5, Roche Diagnostics, Basel, Switzerland) at screening, eGFR $\mathrm{CG} \geq 80 \mathrm{ml} / \mathrm{min}$, genotypic sensitivity to the two investigator-selected $\mathrm{N}[\mathrm{t}] \mathrm{RTIs}$ (GenoSure MG $^{\mathrm{rm}}$ assay, Monogram Biosciences, South San Francisco, CA, USA), and none of the following darunavir
RAMs: V11I, V32I, L33F, I47V, I50V, I54M, I54L, T74P, L76V, I84V or L89V [40]. Exclusion criteria included previous or current use of darunavir, a newly diagnosed AIDS-defining condition, proven or suspected acute hepatitis or treatment for hepatitis $\mathrm{C}$, and females who were pregnant or breastfeeding.

Prior to study start, the trial protocol was reviewed and approved by an independent ethics committee or an institutional review board at each study site. The trial was conducted according to the International Conference on Harmonization guideline for Good Clinical Practice and principles of Good Clinical Practice and Declaration of Helsinki. All patients provided written informed consent.

\section{Study design and treatment}

This was an open-label, single-arm, multicenter, 48-week, Phase IIIb trial (NCT01440569) conducted at 56 sites in the USA to evaluate the safety, efficacy and pharmacokinetics of cobicistat-boosted darunavir (as single agents) plus two fully active N[t]RTIs in HIV-1-infected adults with no darunavir RAMs. The trial consisted of a $\leq 35$-day screening period, a 48-week treatment period and a follow-up visit 30 days after last drug intake or study discontinuation, unless patients participated in an open-label rollover study and continued receiving treatment.

Patients received darunavir $800 \mathrm{mg}$ ( 2 x 400-mg tablets) once daily plus cobicistat (150-mg tablet) once daily, both taken with food and two $\mathrm{N}[\mathrm{t}] \mathrm{RTIs}$, administered orally. For any patients with the M184V/I RAM present at screening, emtricitabine or lamivudine could be included as a third (not fully active) N[t]RTI for the purpose of maintaining M184V/I. Prior to Week 48, changes to the study regimen were only permitted for management of suboptimal antiviral efficacy.

An optional substudy assessed darunavir, cobicistat, emtricitabine and tenofovir pharmacokinetics. The pharmacokinetic substudy included intensive pharmacokinetic sampling over 24 hours and was performed in a subset of patients (target $\mathrm{n}=48$ evaluable) at selected study sites.

\section{Study endpoints and assessments}

The primary endpoint of the study was any treatmentemergent grade 3 (severe) or grade 4 (life threatening) AEs occurring through Week 24. Secondary outcome measures included any treatment-emergent AE through Weeks 24 and 48, including those leading to discontinuation of study drug, and antiviral efficacy at Weeks 24 and 48.

Assessments for AEs (graded according to the Gilead Sciences, Inc. Grading Scale for Severity of Adverse Events and Laboratory Abnormalities) and laboratory parameters (e.g. serum chemistry, hematology, urinalysis, eGFR $\mathrm{CG}_{\text {, }}$ 
plasma VL and $\mathrm{CD} 4{ }^{+}$cell count) were performed at baseline and at Weeks 2, 4, 8, 12, 16, 24, 36 and 48. A 12-lead electrocardiogram was performed at screening only. Safety analyses also included data collected on or after study drug administration through 30 days after the last dose of study drugs for patients who discontinued. AEs were coded using the Medical Dictionary for Regulatory Activities (MedDRA) Version 15.1.

Treatment adherence was assessed by median pill count, which was calculated as the number of pills taken divided by the number of pills prescribed. The proportion of patients in specified adherence categories $(<90 \%$ or $\geq 90 \%$ ) was also calculated.

HIV-1 protease and reverse transcriptase genotype/ phenotype testing (PhenoSense $\mathrm{GT}^{\mathrm{mm}}$ assay, Monogram Biosciences, South San Francisco, CA, USA) was performed on samples from patients with VL $\geq 400$ HIV-1 RNA copies/ml who had a suboptimal virologic response (VL $<1 \log _{10}$ HIV-1 RNA copies/ml reduction from baseline and $\geq 50$ HIV-1 RNA copies/ml at the Week 8 visit, confirmed at the Week 12 visit) or who had a confirmed virologic rebound (VL $<50$ HIV-1 RNA copies/ $\mathrm{ml}$ followed by a confirmed VL $\geq 400 \mathrm{HIV}-1$ RNA copies/ $\mathrm{ml}$ or a $>1 \log _{10}$ HIV-1 RNA copies/ml increase in VL from the nadir) or discontinued (after Week 8) while receiving study drugs. Baseline protease/reverse transcriptase phenotyping was performed retrospectively on patients with confirmed virologic failure only if they showed evidence of reduced susceptibility to darunavir or $\mathrm{N}[\mathrm{t}] \mathrm{RTIs}$ in the background regimen.

\section{Pharmacokinetic measurements}

For the whole study population, sparse blood samples for analysis of study drug plasma concentrations were collected over 24 hours at Weeks 2, 4, 8, 12, 16, 24, 36 and 48. For the pharmacokinetic substudy, plasma samples were collected predose, 1, 2, 3, 3.5, 4, 4.5, 5, 6, 8, 10, 12 and 24 hours post-dose at a visit between Weeks 2 and 8 . Darunavir [41], cobicistat [14], emtricitabine [42] and tenofovir [42] plasma concentrations were assayed using validated liquid chromatography-mass spectrometry/mass spectrometry, with a lower limit of quantification of $5 \mathrm{ng} / \mathrm{ml}$ for darunavir, cobicistat and emtricitabine and $10 \mathrm{ng} / \mathrm{ml}$ for tenofovir.

For the pharmacokinetic substudy, steady-state pharmacokinetic parameters $\left(C_{\max }, C_{\min }\right.$ and $\left.\mathrm{AUC}_{24 \mathrm{~h}}\right)$ were obtained using non-compartmental analysis (WinNonlin software version 6.2, Pharsight Corporation, Mountain View, CA, USA). The intensive pharmacokinetic substudy data was used to revise an existing 2-compartment population pharmacokinetic model with first-order absorption [43]. The population pharmacokinetic model was then used to derive individual empirical Bayes estimates of darunavir exposure $\left(\mathrm{AUC}_{24 \mathrm{~h}}\right.$ and $\left.\mathrm{C}_{0 \mathrm{~h}}\right)$ at all visits using NONMEM.

Pharmacokinetic/pharmacodynamic relationships were assessed using darunavir exposure and virologic response at Week 48. The absence or presence of select AEs (rash, diarrhea, nausea or vomiting) and worst change in laboratory parameters (alkaline phosphatase, alanine transaminase, aspartate aminotransferase, amylase, lipase, glucose, total cholesterol, low-density lipoprotein-cholesterol, highdensity lipoprotein-cholesterol or triglyceride) by darunavir $\mathrm{AUC}_{24 \mathrm{~h}}$ was evaluated.

\section{Data analyses}

Power calculations prior to study design calculated a sample size of 300 patients would provide a $95 \%$ chance of observing $\geq 1$ grade 3 or $4 \mathrm{AE}$ if the true incident rate of the $\mathrm{AE}$ was $1 \%$. This sample size would also produce a two-sided $95 \% \mathrm{CI}$ with a half-width of $4.7 \%$ based on an assumed virologic response rate for PIs (proportion of patients with VL $<50$ HIV-1 RNA copies/ml) of $80 \%$.

The ITT population included all patients who were enrolled in the study and received at least one dose of darunavir and cobicistat.

Given the association between tenofovir and renal and bone events, and that the majority of the patients were receiving this therapy, a prespecified analysis of selected renal events (Fanconi syndrome, renal failure and renal tubular disorder) and bone fractures was conducted.

The primary efficacy analysis was the virologic response rate at Week 24 or 48 by the Snapshot algorithm [44]. Virologic failure was defined as VL $\geq 50 \mathrm{HIV}-1$ RNA copies/ml, discontinuation of study drug prior to Week 24 or 48 due to lack of efficacy, or discontinuation due to other reasons with last available VL $>50$ HIV-1 RNA copies/ml. Patients with no virologic data in the Week 24 or 48 window were classified as treatment failures. Secondary efficacy analyses included virologic response rates according to the TLOVR imputation algorithm and the $\mathrm{M}=\mathrm{F}$ analysis.

\section{Competing interests}

KT has research support from Bristol-Myers Squibb (BMS), Gilead Sciences, Merck, Vertex and ViiV healthcare. GC declares no conflicts of interest or financial disclosures except financial payments for research studies

conducted. FLT, TNK, AB, TVdC and MO are full-time employees of Janssen Pharmaceuticals. WG, NM, JMC, MWF and JS are full-time employees of Gilead Sciences, Inc.

\section{Authors' contributions}

KT and GC - participated in recruiting significant numbers of patients to the trial and reported data for those patients. FLT, TNK, AB, TVdC, MO, WG, NM, JMC, MWF and JS - all had a significant involvement in the data analyses. All authors - involved in the development of the primary manuscript, interpretation of data, have read and approved the final version, and have met the criteria for authorship as established by the ICMJE. 


\section{Acknowledgments}

We would like to thank the patients and their families, investigators, study center staff and Gilead study personnel, in particular Anne Thomas and Julie Peloquin, and the following individuals for their input into this manuscript: Ines Adriaenssen, David Anderson, Goedele De Smedt, Erkki Lathouwers, Christiane Moecklinghoff and Robert Ryan from Janssen Pharmaceuticals. We also thank Bruce Green from Model Answers Pty Ltd, who has provided services to Janssen on the population pharmacokinetic modeling. This study was co-sponsored/supported by Janssen Pharmaceuticals, Ireland, and Gilead Sciences Inc, Foster City, CA, USA. Medical writing support was provided by lan Woolveridge of Gardiner-Caldwell Communications, Macclesfield, UK, part of KnowledgePoint360, an Ashfield company; this support was funded by Janssen Pharmaceuticals.

\section{Previous presentation of data}

Pharmacokinetics and pharmacodynamics of darunavir $800 \mathrm{mg}$ once-daily when coadministered with cobicistat $150 \mathrm{mg}$ once-daily in HIV-1-infected patients with no darunavir resistance-associated mutations (RAMs): GS-US216-0130 week 48 results. Kakuda TN, et al. 15th International Workshop on Clinical Pharmacology of HIV \& Hepatitis Therapy. Abstract P_49. Phase IIIb, open-label, single-arm trial of darunavir/cobicistat: Week 48 subgroup analysis of HIV-1-infected, treatment-naïve adults. Tashima K, et al. 12th International Congress on Drug Therapy in HIV Infection. Abstract P240.

\section{Author details}

'Alpert Medical School of Brown University, The Miriam Hospital, 164 Summit Avenue, Providence, RI 02906, USA. ${ }^{2}$ Gordon Crofoot Research, Houston, TX, USA. ${ }^{3}$ Janssen Research \& Development LLC, Titusville, NJ, USA. ${ }^{4}$ Janssen Research \& Development, Beerse, Belgium. ${ }^{5}$ Janssen Infectious Diseases BVBA, Beerse, Belgium. ${ }^{6}$ Gilead Sciences, Foster City, CA, USA.

Received: 28 July 2014 Accepted: 9 November 2014 Published: 1 December 2014

\section{References}

1. DHHS guidelines: Panel on antiretroviral guidelines for adults and adolescents. Guidelines for the use of antiretroviral agents in HIV-1-infected adults and adolescents. Department of Health and Human Services. [http://aidsinfo.nih.gov/ContentFiles/ AdultandAdolescentGL.pdf]

2. Thompson MA, Aberg JA, Hoy JF, Telenti A, Benson C, Cahn P, Eron JJ, Günthard HF, Hammer SM, Reiss P, Richman DD, Rizzardini G, Thomas DL, Jacobsen DM, Volberding PA: Antiretroviral treatment of adult HIV infection: 2012 Recommendations of the International Antiviral Society-USA Panel. JAMA 2012, 308:387-402.

3. Williams I, Churchill D, Anderson J, Boffito M, Bower M, Cairns G, Cwynarski K, Edwards S, Fidler S, Fisher M, Freedman A, Geretti AM, Gilleece Y, Horne R, Johnson M, Khoo S, Leen C, Marshall N, Nelson M, Orkin C, Paton N, Phillips A, Post F, Pozniak A, Sabin C, Trevelion R, Ustianowski A, Walsh J, Waters L, Wilkins E, Winston A, Youle M: British HIV Association guidelines for the treatment of HIV-1-positive adults with antiretroviral therapy 2012. HIV Med 2012, 13(Suppl. 2):1-85.

4. EACS: European guidelines for treatment of HIV infected adults in Europe. Version 7.02, updated June 2014. [http://www.eacsociety.org/ Portals/0/140601_EACS\%20EN7.02.pdf]

5. Ortiz R, Dejesus E, Khanlou H, Voronin E, van Lunzen J, Andrade-Villanueva J, Fourie J, De Meyer S, De Pauw M, Lefebvre E, Vangeneugden T, SpinosaGuzman S: Efficacy and safety of once-daily darunavir/ritonavir versus lopinavir/ritonavir in treatment-naive HIV-1-infected patients at week 48. AIDS 2008, 22:1389-1397.

6. Mills AM, Nelson M, Jayaweera D, Ruxrungtham K, Cassetti I, Girard PM, Workman C, Dierynck I, Sekar V, Abeele CV, Lavreys L: Once-daily darunavir/ritonavir vs. lopinavir/ritonavir in treatment-naive, HIV-1-infected patients: 96-week analysis. AIDS 2009, 23:1679-1688.

7. Orkin C, DeJesus E, Khanlou H, Stoehr A, Supparatpinyo K, Lathouwers E, Lefebvre E, Opsomer M, Van de Casteele T, Tomaka F: Final 192-week efficacy and safety of once-daily darunavir/ritonavir compared with lopinavir/ritonavir in HIV-1-infected treatment-naïve patients in the ARTEMIS trial. HIV Med 2013, 14:49-59.

8. Cahn P, Fourie J, Grinsztejn B, Hodder S, Molina JM, Ruxrungtham K, Workman C, Van De Casteele T, De Doncker P, Lathouwers E, Tomaka F:
Week 48 analysis of once-daily vs. twice-daily darunavir/ritonavir in treatment-experienced HIV-1-infected patients. AIDS 2011, 25:929-939.

9. Hull MW, Montaner JS: Ritonavir-boosted protease inhibitors in HIV therapy. Ann Med 2011, 43:375-388.

10. Vermeir M, Lachau-Durand S, Mannens G, Cuyckens F, van Hoof B, Raoof A: Absorption, metabolism, and excretion of darunavir, a new protease inhibitor, administered alone and with low-dose ritonavir in healthy subjects. Drug Metab Dispos 2009, 37:809-820.

11. Samaras K, Richardson R, Carr A: Postprandial lipid effects of low-dose ritonavir vs. raltegravir in HIV-uninfected patients. AIDS 2010, 24:1727-1731.

12. Foisy MM, Yakiwchuk EM, Hughes CA: Induction effects of ritonavir: implications for drug interactions. Ann Pharmacother 2008, 42:1048-1059.

13. Xu L, Liu H, Murray B, Callebaut C, Lee MS, Hong A, Strickley RG, Tsai LK, Stray KM, Wang Y, Rhodes GR, Desai MC: Cobicistat (GS-9350): a potent and selective inhibitor of human CYP $3 \mathrm{~A}$ as a novel pharmacoenhancer. ACS Med Chem Lett 2010, 1:209-213.

14. Mathias AA, German P, Murray BP, Wei L, Jain A, West S, Warren D, Hui J, Kearney BP: Pharmacokinetics and pharmacodynamics of GS-9350: a novel pharmacokinetic enhancer without anti-HIV activity. Clin Pharmacol Ther 2010, 87:322-329.

15. Elion R, Cohen C, Gathe J, Shalit P, Hawkins T, Liu HC, Mathias AA, Chuck SL, Kearney BP, Warren DR, GS-US-216-0105 Study Team: Phase 2 study of cobicistat versus ritonavir each with once-daily atazanavir and fixeddose emtricitabine/tenofovir DF in the initial treatment of HIV infection. AIDS 2011, 25:1881-1886.

16. Gallant JE, Koenig E, Andrade-Villanueva J, Chetchotisakd P, DeJesus E, Antunes F, Arastéh K, Moyle G, Rizzardini G, Fehr J, Liu Y, Zhong L, Callebaut C, Szwarcberg J, Rhee MS, Cheng AK: Cobicistat versus ritonavir as a pharmacoenhancer of atazanavir plus emtricitabine/tenofovir disoproxil fumarate in treatment-naive HIV type 1-infected patients: week 48 results. J Infect Dis 2013, 208:32-39.

17. Shah BM, Schafer JJ, Priano J, Squires KE: Cobicistat: a new boost for the treatment of human immunodeficiency virus infection. Pharmacother 2013, 33:1107-1116.

18. Sterrantino G, Santoro L, Bartolozzi D, Trotta M, Zaccarelli M: Self-reported adherence supports patient preference for the single tablet regimen (STR) in the current CART era. Patient Prefer Adherence 2012, 6:427-433.

19. Buscher A, Hartman C, Kallen MA, Giordano TP: Impact of antiretroviral dosing frequency and pill burden on adherence among newly diagnosed, antiretroviral-naive HIV patients. Int J STD AIDS 2012, 23:351-355.

20. Kauf TL, Davis KL, Earnshaw SR, Davis EA: Spillover adherence effects of fixed-dose combination HIV therapy. Patient Prefer Adherence 2012, 6:155-164.

21. Juday T, Gupta S, Grimm K, Wagner S, Kim E: Factors associated with complete adherence to HIV combination antiretroviral therapy. HIV Clin Trials 2011, 12:71-78

22. Bangalore S, Kamalakkannan G, Parkar S, Messerli FH: Fixed dose combinations improve medication compliance: a meta-analysis. Am J Med 2007, 120:713-719.

23. Cohen C, Elion R, Ruane P, Shamblaw D, DeJesus E, Rashbaum B, Chuck SL, Yale K, Liu HC, Warren DR, Ramanathan S, Kearney BP: Randomized, phase 2 evaluation of two single-tablet regimens elvitegravir/cobicistat/ emtricitabine/tenofovir disoproxil fumarate versus efavirenz/emtricitabine/ tenofovir disoproxil fumarate for the initial treatment of HIV infection. AIDS 2011, 25:F7-F12.

24. DeJesus E, Rockstroh JK, Henry K, Molina JM, Gathe J, Ramanathan S, Wei X, Yale K, Szwarcberg J, White K, Cheng AK, Kearney BP, GS-236-0103 Study Team: Co-formulated elvitegravir, cobicistat, emtricitabine, and tenofovir disoproxil fumarate versus ritonavir-boosted atazanavir plus co-formulated emtricitabine and tenofovir disoproxil fumarate for initial treatment of HIV-1 infection: a randomised, double-blind, phase 3, non-inferiority trial. Lancet 2012, 379:2429-2438.

25. Rockstroh JK, DeJesus E, Henry K, Molina JM, Gathe J, Ramanathan S, Wei X, Plummer A, Abram M, Cheng AK, Fordyce MW, Szwarcberg J, GS-236-0103 Study Team: A randomized, double-blind comparison of coformulated elvitegravir/cobicistat/emtricitabine/tenofovir DF vs ritonavir-boosted atazanavir plus coformulated emtricitabine and tenofovir DF for initial treatment of HIV-1 infection: analysis of week 96 results. J Acquir Immune Defic Syndr 2013, 62:483-486. 
26. Sax PE, DeJesus E, Mills A, Zolopa A, Cohen C, Wohl D, Gallant JE, Liu HC, Zhong L, Yale K, White K, Kearney BP, Szwarcberg J, Quirk E, Cheng AK, GS-US-236-0102 study team: Co-formulated elvitegravir, cobicistat, emtricitabine, and tenofovir versus co-formulated efavirenz, emtricitabine, and tenofovir for initial treatment of HIV-1 infection: a randomised, double-blind, phase 3 trial, analysis of results after 48 weeks. Lancet 2012, 379:2439-2448.

27. Zolopa A, Sax PE, DeJesus E, Mills A, Cohen C, Wohl D, Gallant JE, Liu HC, Plummer A, White KL, Cheng AK, Rhee MS, Szwarcberg J, GS-US-236-0102 Study Team: A randomized double-blind comparison of coformulated elvitegravir/cobicistat/emtricitabine/tenofovir disoproxil fumarate versus efavirenz/emtricitabine/tenofovir disoproxil fumarate for initial treatment of HIV-1 infection: analysis of week 96 results. J Acquir Immune Defic Syndr 2013, 63:96-100

28. Wohl DA, Cohen C, Gallant JE, Mills A, Sax PE, DeJesus E, Zolopa A, Liu HC, Plummer A, White KL, Cheng AK, Rhee MS, Szwarcberg J, GS-US-236-0102 Study Team: A randomized, double-blind comparison of single-tablet regimen elvitegravir/cobicistat/emtricitabine/tenofovir DF versus single-tablet regimen efavirenz/emtricitabine/tenofovir DF for initial treatment of HIV-1 infection: analysis of week 144 results. J Acquir Immune Defic Syndr 2014, 65:e118-e120.

29. German P, Liu HC, Szwarcberg J, Hepner M, Andrews J, Kearney BP, Mathias A: Effect of cobicistat on glomerular filtration rate in subjects with normal and impaired renal function. J Acquir Immune Defic Syndr 2012, 61:32-40.

30. Mathias A, Liu HC, Warren D, Sekar V, Kearney BP: Relative Bioavailability and Pharmacokinetics of Darunavir When Boosted With the Pharmacoenhancer GS-9350 VersuS RTV. Sorrento, Italy: Eleventh International Workshop on Clinical Pharmacology of HIV Therapy; 2010. Abstract 28.

31. Kakuda TN, Opsomer M, Timmers M, Iterbeke K, Van De Casteele T, Hillewaert V, Petrovic R, Hoetelmans RMW: Pharmacokinetics of darunavir in fixed-dose combination with cobicistat compared with coadministration of darunavir and ritonavir as single agents in healthy volunteers. J Clin Pharmacol 2014, 54:949-957.

32. Kakuda TN, Van De Casteele T, Petrovic R, Neujens M, Salih H, Opsomer M, Hoetelmans RMW: Bioequivalence of a darunavir/cobicistat fixed-dose combination tablet versus single agents and food effect in healthy volunteers. Antivir Ther 2014, 19:597-606.

33. Sekar V, Vanden Abeele C, Van Baelen B, Vis P, Lavreys L, de Pauw M, Hoetelmans RMW: Pharmacokinetic-Pharmacodynamic Analyses of Once-Daily Darunavir-Ritonavir in the ARTEMIS Study. Boston, MA: Fifteenth Conference on Retroviruses and Opportunistic Infections; 2008. Abstract 769

34. Sekar V, De La Rosa G, Van de Casteele T: Pharmacokinetic and pharmacodynamic analyses of once- and twice-daily darunavir/ritonavir in the ODIN trial. J Int AIDS Soc 2010, 13(Suppl 4):185.

35. Boffito M, Miralles D, Hill A: Pharmacokinetics, efficacy, and safety of darunavir/ritonavir $800 / 100 \mathrm{mg}$ once-daily in treatment-naive and -experienced patients. HIV Clin Trials 2008, 9:418-427.

36. Agarwala S, Eley T, Villegas C, Wang EH, Grasela D: Pharmacokinetic Interaction Between Tenofovir and Atazanavir Coadministered With Ritonavir in Healthy Subjects. Quebec: Sixth International Workshop on Clinical Pharmacology of HIV Therapy; 2005. Abstract 11.

37. Hoetelmans RM, Mariën K, De Pauw M, Hill A, Peeters M, Sekar V, De Doncker P, Woodfall B, Lefebvre E: Pharmacokinetic interaction between TMC114/ritonavir and tenofovir disoproxil fumarate in healthy volunteers. Br J Clin Pharmacol 2007, 64:655-661.

38. Kearney BP, Mathias A, Mittan A, Sayre J, Ebrahimi R, Cheng AK: Pharmacokinetics and safety of tenofovir disoproxil fumarate on coadministration with lopinavir/ritonavir. J Acquir Immune Defic Syndr 2006, 43:278-283.

39. Van Sanden S, Thilakarathne P, Opsomer M, Mrus J, Vanveggel S, Lathouwers E, Adriaenssen I: Non-Inferiority of Once-Daily Cobicistat-Boosted Darunavir Versus Ritonavir-Boosted Darunavir in HIV-1-Infected Patients: A Comparative Analysis of Pooled Phase 3 Data. Amsterdam, The Netherlands: ISPOR 17th Annual European Congress; 2014. Poster PIN1.

40. Johnson VA, Calvez V, Gunthard HF, Paredes R, Pillay D, Shafer RW, Wensing AM, Richman DD: Update of the drug resistance mutations in HIV-1: March 2013. Top Antivir Med 2013, 21:6-14.

41. Schöller-Gyüre M, Kakuda TN, Sekar V, Woodfall B, De Smedt G, Lefebvre E, Peeters M, Hoetelmans RM: Pharmacokinetics of darunavir/ritonavir and
TMC125 alone and coadministered in HIV-negative volunteers. Antivir Ther 2007, 12:789-796.

42. Blum MR, Chittick GE, Begley JA, Zong J: Steady-state pharmacokinetics of emtricitabine and tenofovir disoproxil fumarate administered alone and in combination in healthy volunteers. J Clin Pharmacol 2007, 47:751-759.

43. Vis $P$, Sekar $S$, van Schaick E, Hoetelmans R: Development and Application of a Population Pharmacokinetic Model of TMC114 in Healthy Volunteers and HIV-1 Infected Subjects After Administration of TMC114 in Combination With Low-Dose Ritonavir. Bruges, Belgium: Fifteenth Annual Meeting of the Population Approach Group in Europe (PAGE); 2006. Abstract 964.

44. FDA Guidance for Industry: Antiretroviral drugs using plasma HIV RNA measurements - clinical considerations for accelerated and traditional approval, prepared by the Division of Antiviral Drug Products: Office of Drug Evaluation IV in the Centre for Drug Evaluation and Research (CDER), Appendix B (October 2002). [http://www.fda.gov/downloads/Drugs/ GuidanceComplianceRegulatoryInformation/Guidances/UCM070968.pdf]

doi:10.1186/1742-6405-11-39

Cite this article as: Tashima et al: Cobicistat-boosted darunavir in HIV-1-infected adults: week 48 results of a Phase IIlb, open-label single-arm trial. AIDS Research and Therapy 2014 11:39.

\section{Submit your next manuscript to BioMed Central and take full advantage of:}

- Convenient online submission

- Thorough peer review

- No space constraints or color figure charges

- Immediate publication on acceptance

- Inclusion in PubMed, CAS, Scopus and Google Scholar

- Research which is freely available for redistribution 